\title{
Determination of the Parameters of Technological Schemes for the Development of Coal Seams Prone to Spontaneous Combustion using Computer Simulation
}

\author{
Sergey Meshkov ${ }^{1}$ \\ ${ }^{1}$ JSC SUEK Kuzbass, 652507, 1, Vasilyev St., Leninsk-Kuznetsky, Russia
}

\begin{abstract}
The study considers thr problem of endogenous fire hazard in underground mining of coal seams prone to spontaneous combustion. The main trends in the development of modern technology of underground coal mining are shown. The interaction of air-gas-dynamic and geomechanical processes in the development of coal seams by longwall mining is considered. The possibilities of computer simulation of air-gas-dynamic processes in the extraction districts of modern coal mines are considered. The significant influence of geological and mining conditions of mining operations on the distribution of air flow in extraction districts and the efficiency of gas emission control in the workings of the extraction districts are shown. The design scheme and the results of numerical studies (methane and oxygen concentration fields) are given. It is concluded that it is necessary to determine the rational parameters of the preparation, ventilation, isolated drainage and degassing schemes when developing gasbearing coal seams that are prone to spontaneous combustion. Recommendations are given on improvement of the safety in mining coal seams that are prone to spontaneous combustion.
\end{abstract}

\section{Introduction}

Endogenous fires present one of the most severe types of accidents in coal mines, causing significant economic damage associated with both the direct costs of their liquidation and long downtime of coal mining enterprises, as well as the loss of reserves prepared for extraction. Endogenous fires pose a significant danger to underground miners, due to the release of toxic gases into a confined space of mine workings. In addition, endogenous fires in gas mines can cause ignition and explosions of methane and coal dust.

The mechanism of spontaneous combustion of coal is currently quite well studied. The conditions required for spontaneous coal combustion are as follows: presence of reactive coal, a constant supply of oxygen, the possibility of heat accumulation due to low air velocity and accumulation of sufficient volume. Despite the knowledge of the process of spontaneous combustion of coal in the mines, endogenous fires continue to occur due to the influence of a whole complex of natural and mining factors which can vary both in the space of the mine and in time. The applicable instructions contain the basic requirements that ensure the reduction of endogenous fire hazard. However, modern trends in 
underground coal mining, which are associated with an increase in the intensity of reserves mining, lead to a significant change in the conditions of coal seams development and an increase in the endogenous fire hazard of mining [1-3]. Increasing output per coal faces during the mining of gas-bearing coal seams leads to an increase in the methane content of extraction districts. To ensure effective management of methane release in Kuzbass, a combined scheme of ventilation in the extraction district is used with an isolated drainage of methane-air mixture through the goaf and degassing of the goaf via boreholes drilled from the surface [4-5]. Due to the controlled air leakage through the goaf, isolation of the longwall face is ensured, however, the use of such a scheme requires additional substantiation of its parameters to reduce production costs and eliminate spontaneous combustion of coal in the goaf area. It should be noted that the increase in the output per coal faces has led to a change in the main roof caving increment and an increase, as a result, in the permeability of the goaf [6-10]. The increase in the length of the longwall and in the output per face led to a significant change in the air-gas-dynamic conditions in the extraction districts, thus preventing the effective use of the previously obtained dependencies and effective management of the methane release. The analysis of world experience shows that three-dimensional computer modeling using the methods and approaches of continuum mechanics is successfully used to substantiate the parameters of preparation, ventilation and degassing schemes [11-12], and to ensure endogenous fire safety [13-16].

\section{Materials and methods}

The studies were conducted using continuum mechanics approaches. A three-dimensional air-gas-dynamic model of the extraction district has been developed for the study. The three-dimensional model included district development headings, the longwall face area, the goaf filled with caved rock. The design model used in numerical studies is presented in Figure 1. The goaf area was modeled as a porous body with varying permeability in accordance with the approaches described in the works of other researchers [13-19].

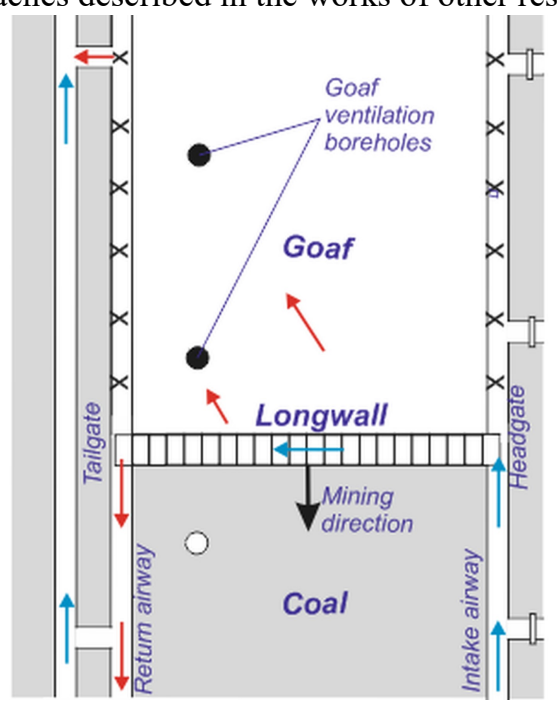

Fig. 1. Design scheme.

The following sources of methane release were assigned at the extraction district: in the goaf - from the underworked and overworked seams, from the surface of the face and from the cut coal. At the initial stage, the parameters of gas emission, degassing and 
ventilation were assigned based on actual mine data for further comparison of simulation results and model adjustment. Carrying out numerical studies of air-gas-dynamic processes at the extraction districts using the ANSYS software package included the following successive actions: assigning the geometry of mine workings and goafs taking into account specific mining and geological conditions; assigning the parameters of the $3 \mathrm{D}$ grid and breaking the model down to elements; determining the physical parameters of the model and marginal conditions (input-output parameters), carrying out a numerical solution, processing and visualizing the results, analysing the results.

\section{Results and discussion}

As a result of the conducted numerical studies, the fields of oxygen and methane distribution in the extraction district were obtained for various parameters of preparation, ventilation and degassing. The main parameter of the preparation, the influence of which was taken into account when conducting research, is the distance between the air crosscuts. Figures 2 and 3 show, as an example of the results obtained, the distribution of methane and oxygen, respectively, in the extraction district in a plane parallel to the seam at a height of 2 $\mathrm{m}$ from its floor.

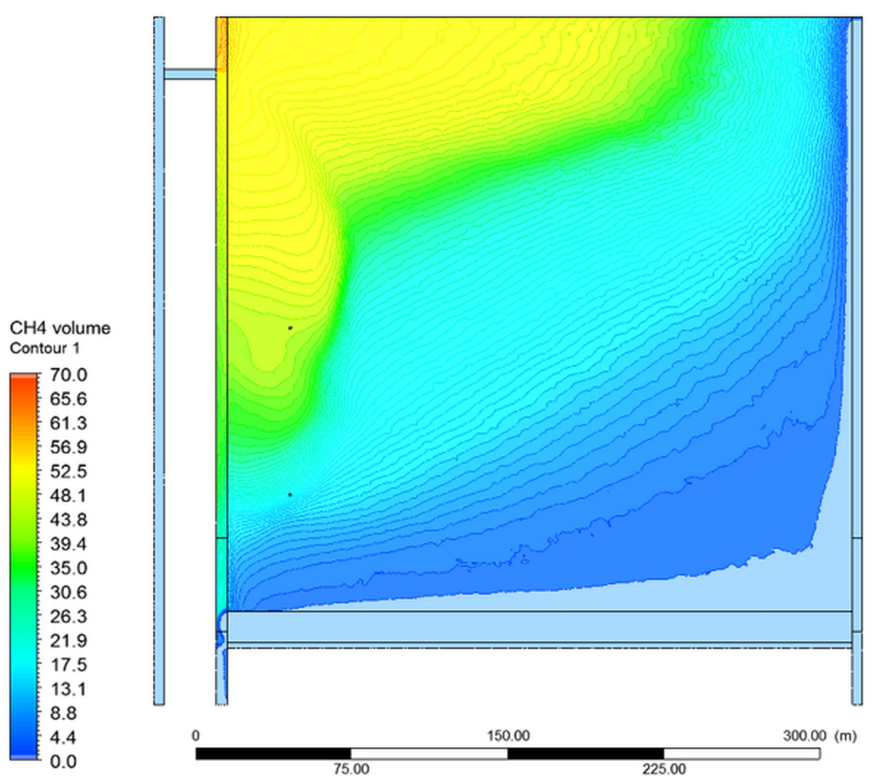

Fig. 2. Methane concentration in the extraction district, \%.

Figure 2 shows that the highest concentration in the extraction district is observed in the goaf from the side of return airway which is explained by the removal of methane to this part by air bleeding through the goaf. The lowest concentration of methane is observed from the side of the intake airway, which is also explained by air leaks. 


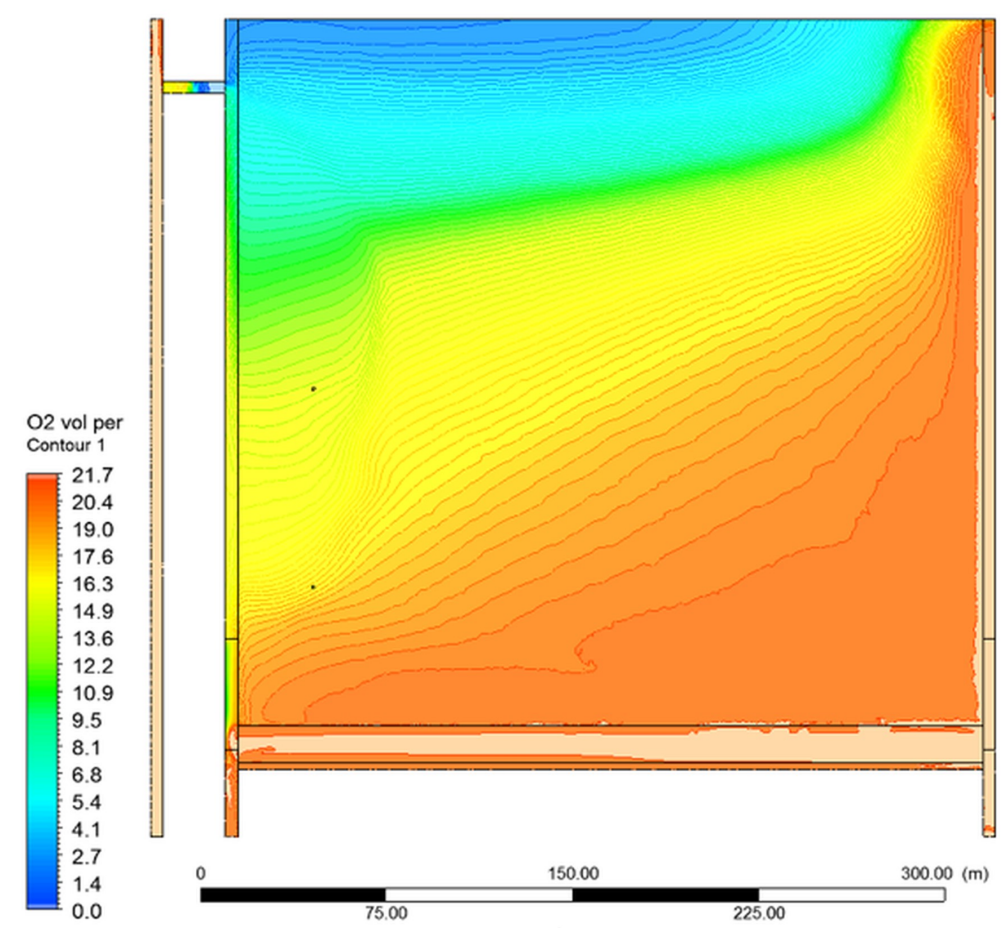

Fig. 3. Oxygen concentration in the extraction district, $\%$.

The study has established that the oxygen concentration in the goaf (Figure 3) remains within the fire hazardous values $(>10 \%$ ) at a considerable distance (up to $400 \mathrm{~m}$ and more) from the coal face. A significant concentration of methane is observed in the areas with increased permeability, which include caved workings and a part of the longwall mined-out area. Taking into account the possibility of the formation of coal accumulations as a result of, for example, coal spalling in the sidewalls of coal pillars, increased permeability zones in caved workings can pose an increased endogenous fire hazard.

\section{Conclusions}

Computer simulation is a modern tool for substantiating the parameters of technological schemes for mining gas-bearing coal seams that are prone to spontaneous combustion. Three-dimensional modeling allows us to estimate the influence of the main geological and mining factors on the distribution of gases in extraction areas and to identify the presence of dangerous zones. The studies have found the following main parameters of technological schemes applied in mining the coal seams that are prone to spontaneous combustion using combined schemes for ventilation in extraction districts with an isolated drainage for methane-air mixture and goaf degassing using vertical boreholes drilled from the earth's surface: the distance between air crosscuts, the distance from the working face to the current degassing borehole, air flow and methane content in the extraction district.

To improve safety in mining the seams that are prone to spontaneous combustion, it is necessary to consider the distribution of oxygen in the extraction district, taking into account the duration of the ventilation of the most fire hazardous zones. Particular attention 
should be paid to the period of equipment re-installation which, as a rule, exceeds the period of coal spontaneous combustion.

A necessary condition for obtaining adequate results in modeling air-gas-dynamic processes in the extraction areas of modern mines is the correct setting of the goaf parameters (permeability and porosity), which largely determine the air flows in the extraction area. The goaf parameters can be determined at the initial stage (when creating the model) in accordance with the methods described in [11-19], but it requires further comparison with actual data and specification taking into account the geological and mining conditions of a particular mine.

\section{References}

1. A. V. Stebnev, D. A. Zadkov, V. V. Gabov, S. G. Mukhortikov, Eurasian mining, 2, 28 (2017)

2. N. V. Palyanova, D. A. Zadkov, S. G. Chubukova, Eurasian mining, 1, 3 (2017)

3. K. L. Nguyen, V. V. Gabov, D. A. Zadkov, Eurasian mining, 2, 22 (2018)

4. O. I. Kazanin A. A. Sidorenko E. A. Vinogradov, ARPN Journal of Engineering and Applied Sciences, 12:7, 2259 (2017)

5. O. I. Kazanin, A. A. Sidorenko, ARPN Journal of Engineering and Applied Sciences, 12 (1) 227 (2017)

6. A. A. Sidorenko, V. V. Ivanov, S. A. Sidorenko, International Journal of Civil Engineering and Technology, 10:1, 844 (2019)

7. O. I. Kazanin, A. A. Sidorenko, ARPN Journal of Engineering and Applied Sciences, 12:5, 1458 (2017)

8. A. A. Sidorenko, Yu. G. Sirenko, S. A. Sidorenko, Eurasian Mining, 1, 3 (2018)

9. O. I. Kazanin, A. A. Sidorenko, Y. G. Sirenko, ARPN Journal of Engineering and Applied Sciences, 14:3, 732 (2019)

10. A. A. Sidorenko, V. V. Ivanov, ARPN Journal of Engineering and Applied Sciences, 11:7, 4448 (2016)

11. D. M. Worrall Modeling gas flows in longwall coal mines using Computational Fluid Dynamics, Ph.D. Thesis (The Colorado School of Mines, 2012)

12. O.I. Kazanin, A. A. Sidorenko, Y. G. Sirenko, ARPN Journal of Engineering and Applied Sciences, 13:4, 1534 (2018)

13. V. K. Singh, Procedia Engineering, 62, 78 (2013)

14. Y. Lu, S. Shi, Q. Ye, Z. Tian, Journal of Residuals Science \& Technology, 14:3, 373 (2017)

15. A. C. Smith, L. Yuan, Mining Engineering, 60:8, 61 (2008)

16. L. Yuan, A.C. Smith, Journal of loss prevention in process industries, 25, 131 (2011)

17. G. S. Esterhuizen, C. O. Karacan, Proceeding of the 40th U.S. Rock Mechanics Symposium. Alexandria, VA: American Rock Mechanics Association (2005)

18. C. Ö. Karacan, Transport in Porous Media, 82:2, 413 (2009)

19. C. Zhang, S. Tu, L. Zhang, Q. Bai, Y. Yuan, F. Wang, Journal of Geophysics and Engineering, 13:2, 181 (2016) 